\title{
Elaboration of a probiotic oblea from whey fermented using Lactobacillus acidophilus or Bifidobacterium infantis
}

\author{
G. Trujillo-de Santiago, ${ }^{\star}$ C. P. Sáenz-Collins, ${ }^{\star}$ and C. Rojas-de Gante ${ }^{1}$ \\ *Tecnológico de Monterrey, Campus Monterrey, Centro de Biotecnología FEMSA, Escuela de Biotecnología y Alimentos, \\ Ave. Eugenio Garza Sada 2501 Sur Col. Tecnológico, CP 64849, Monterrey, Nuevo León, México \\ †Tecnológico de Monterrey, Campus Ciudad de México, Centro de Biotecnología FEMSA, Departamento de Ingeniería en Biotecnología, \\ Calle del Puente 222 Col. Ejidos de Huipulco, CP 14380 Tlalpan, México, Distrito Federal, México
}

\begin{abstract}
A novel probiotic product was developed, which was formulated as an oblea (wafer-type dehydrated traditional Mexican dessert) using goat sweet whey fermented with Bifidobacterium infantis or Lactobacillus acidophilus. To obtain the probiotic oblea, the fermented whey was formulated with prebiotic carbohydrates (inulin and resistant starch) and gelatin, and the preparation was poured onto a polytetrafluoroethylene-coated nonstick baking pan, dried in a convection oven, and finally dehydrated at a low relative humidity and room temperature $\left(23 \pm 2^{\circ} \mathrm{C}\right)$. The amounts of prebiotic carbohydrates and gelatin to be used in the formulation were determined by a factorial experimental design. An untrained sensory panel evaluated 3 quality characteristics (film formation, homogeneity, and smoothness) in the final product. Three different drying temperatures were tested, namely, 40, 55, and $70^{\circ} \mathrm{C}$. Bacterial survival at each temperature was determined by viable plate-counting. The best formulation, based on the quality characteristics tested, consisted of $58.33 \%$ ( vol/vol) of fermented whey, $8.33 \%(\mathrm{vol} / \mathrm{vol})$ of $6 \%$ (wt/vol) resistant starch dispersion, $16.66 \%$ (vol/ $\mathrm{vol}$ ) of $15 \%(\mathrm{wt} / \mathrm{vol}$ ) inulin solution, and $16.66 \%$ (vol/ vol) of a $10 \%$ (wt/vol) gelatin solution. Drying at 55 $\pm 2^{\circ} \mathrm{C}$ for $2.66 \pm 0.22 \mathrm{~h}$ allowed for concentrations of probiotic bacteria above $9 \log _{10} \mathrm{cfu} / \mathrm{g}$, which is above the minimum concentration required in a probiotic product.
\end{abstract}

Key words: probiotic, oblea, Bifidobacterium infantis, Lactobacillus acidophilus

\section{INTRODUCTION}

Oblea, a traditional dehydrated dessert very popular in Mexico, consists of a thin sheet similar to a wafer

\footnotetext{
Received February 7, 2012.

Accepted August 12, 2012.

${ }^{1}$ Corresponding author: crd@itesm.mx
}

biscuit, usually made of wheat flour, that is very dry, fragile, and crispy. Obleas are enjoyed alone or with caramel drops, pumpkin seeds, or a cajeta (goat's milk candy) filling. We chose this presentation for the novel probiotic product because of its convenience (ready to eat), its potential stability and long shelf life (because of the low water content of the final product), and the popularity of obleas among the Mexican population, particularly children.

The market for probiotic products, in both food and pharmaceutical presentations, has grown considerably in the last decade (Jankovic et al., 2010; Rivera-Espinoza and Gallardo-Navarro, 2010; de Barcellos and Lionello, 2011) because of their proven therapeutic effects. Several studies have demonstrated the health benefits of Bifidobacterium infantis and Lactobacillus acidophilus, the probiotic strains used in the present study, in gastrointestinal disease prevention and treatment, immune system modulation, anticholesteremic effects, and anticancer activity (Pereira and Gibson, 2002; Parkes et al., 2010; Zhu et al., 2011; Konieczna et al., 2012).

For a product to be considered probiotic, it must meet a minimum requirement for the concentration of probiotic microorganisms. As a guide, the International Dairy Federation and the Japan Fermented Milk Association suggest a threshold of $10^{7} \mathrm{cfu} / \mathrm{g}$ or $10^{7} \mathrm{cfu} / \mathrm{mL}$ of product (Sultana et al., 2000; Kailasapathy, 2002; Farnworth, 2008). However, it is not uncommon to observe viable counts lower than this value in commercial probiotic products (Damin et al., 2008; Olson and Aryana, 2008; Klayraunga et al., 2009). Fermented dairy formulations are still the most common and traditional probiotic products in the market. These types of products are highly susceptible to spoilage because of their high water activity and nutrient content. In addition, sustaining a high enough viable probiotic count in these products over time is a challenge (Kailasapathy, 2006). It is well documented that the viable probiotic count decreases rapidly above refrigeration temperatures. For example, the viable probiotic count decreases rapidly 
in yogurts exposed to room temperature (Scharl et al., 2011). Therefore, a rigorous cold chain is mandatory to ensure quality in fermented liquid (or semisolid) formulations (Scharl et al., 2011). However, implementing such a cold chain entails high costs and complicated logistics (McKinnon and Campbell, 1998). Strategies such as microencapsulation (Chen et al., 2012), the use of protective agents, or dehydration techniques have been proposed to minimize the loss of beneficial bacteria in probiotic products (Araújo et al., 2010; Chávarri et al., 2010; Heidebach et al., 2010)

Recently, dehydrated probiotic formulations have received increasing attention (Klayraung et al., 2009; Aguirre-Ezkauriatza et al., 2010; Malmo et al., 2011). Dehydrated products are generally stable at room temperature (Klayraung et al., 2009), which is attractive in terms of cost because their transport and storage does not require a cold chain. In low-humidity probiotic formulations, drying is a key unit operation because a significant decrease in viable bacteria count may occur during exposure to high temperatures (Malmo et al., 2011).

One important aim of the present study was to develop a high value-added product from whey, a by-product of cheese manufacture. Whey is still undervalued in Mexico and other developing countries (Aguirre-Ezkauriatza et al., 2010) and is even considered a potential environmental problem. Because of its high organic load, whey can be a serious contaminant if inadequately disposed of. The world's annual production of whey is approximately 145 million tons, and Mexico produces approximately 1.3 million tons (Carrillo, 2006). GarcíaGaribay et al. (2002) have estimated that Mexico uses only $10 \%$ of the whey it produces to develop valueadded products. Whey is a by-product with a high potential for transformation into a value-added product. Previous work has demonstrated the use of whey as a substrate for probiotic bacteria (Aguirre-Ezkauriatza et al., 2010; Magalhães et al., 2010; Soares et al., 2011).

\section{MATERIALS AND METHODS}

\section{Materials}

Two different probiotic bacteria were used in this study: L. acidophilus ATCC 521 and B. infantis ATCC 17930. Both strains were preserved at $-80 \pm 2^{\circ} \mathrm{C}$ with de Man, Rogosa, and Sharpe (MRS) broth (Difco Laboratories, México City, México) and 20\% glycerol. Goat sweet whey, a by-product of fresh white cheese making, was kindly provided by the cheese manufacturer (Caprico, Nuevo León, Mexico). Low-viscosity chicory inulin and resistant corn starch type 2 (RS) were kindly donated by Texture Innovation Company
(México City, México) and Hi Maize was donated by National Starch (Mexico), respectively. Commercial gelatin (Knox; Kraft Foods, Northfield, IL) was purchased at a local convenience store.

\section{Reactivation of Strains}

Lactobacillus acidophilus and B. infantis were reactivated in $7.5 \mathrm{~mL}$ of MRS broth and cultured in a vacuum incubator (Sheldon Manufacturing Inc., Cornelius, OR) at $38 \pm 2^{\circ} \mathrm{C}$ and a vacuum of $20 \mathrm{mmHg}$. Optical density was monitored at $\lambda=660 \mathrm{~nm}$ using a spectrophotometer (Genesys 10 UV; Thermo Electron, Madison, WI). Successive reactivation stages were conducted in MRS broth (at a volume of $7.5 \mathrm{~mL}$ and using a $10 \%$ volume of inoculum) until the lag phase was eliminated and the specific growth rate (calculated from the linearization of the growth curve) reached a constant value. An additional series of transfers was performed at a scaled volume of $450 \mathrm{~mL}$. Strains were adapted to pasteurized goat sweet whey by a third round of successive transfers until the lag phase was eliminated. The fermented whey was portioned and stored at $4^{\circ} \mathrm{C}$ until used in the fermentation experiments.

\section{Whey Fermentation}

Whey was pasteurized at $72 \pm 2^{\circ} \mathrm{C}$ for 15 to $30 \mathrm{~s}$ before the fermentation experiments. Fermentations were conducted using either L. acidophilus or B. infantis as the fermentative culture (no experiments were conducted with both strains fermenting simultaneously). Volumes of $450 \mathrm{~mL}$ of pasteurized whey were fermented using $10 \%$ ( vol/vol) of inocula. The bacterial concentrations in inocula were $8.29 \pm 0.22$ and $8.49 \pm 0.08 \log _{10}$ $\mathrm{cfu} / \mathrm{mL}$ for L. acidophilus and B. infantis, respectively. Incubation conditions were the same as those described previously for strain reactivation.

Samples from whey fermentation were taken every hour to monitor cell growth, lactose consumption, lactic acid production, and $\mathrm{pH}$ evolution. Growth curves were constructed based on viable plate counts done in MRS agar (Difco Laboratories). Plates were incubated at the same conditions used for strain reactivation.

Lactose consumption and lactic acid production were determined by HPLC with a refractive index detector (Waters Corp., Milford, MA) using an Aminex HPx87H Bio-Rad column (Bio-Rad Laboratories, Hercules, CA)

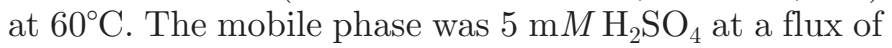
$0.6 \mathrm{~mL} / \mathrm{min}$. The detector temperature was maintained at $50^{\circ} \mathrm{C}$. Samples were previously filtered through a $0.2-\mu \mathrm{m}$ polytetrafluoroethylene membrane (Acrodisc Syringe Filters; Pall Life Sciences, Gloucestershire, UK). Calibration curves for lactose and lactic acid were 
constructed using lactose monohydrate CAS 10039-266 (DEQ, García, Nuevo León, México), and L(+)-lactic acid CAS 79-33-4 (Purac, Gorinchem, the Netherlands) as standards.

\section{Experiments to Determine the Probiotic Oblea Formulation}

In addition to the fermented probiotic whey, food grade additives were used to formulate the probiotic oblea: low-viscosity chicory inulin, RS, and commercial gelatin. These additives were selected because of their reported prebiotic properties (inulin and RS; Ramirez-Farias et al., 2009; Le Leu et al., 2010) and their functional properties (e.g., film formation; Hernandez-Izquierdo and Krochta, 2008). Inulin and gelatin solutions were prepared at 15 and 10\% (wt/vol), respectively. The RS suspension was prepared at $6 \%$ (wt/vol). A factorial $2^{3}$ experimental design was used to determine the amounts of each of these additives in the final formulation. Each additive was evaluated at 2 different levels (8.33 and $16.66 \%$ of the final volume of the preparation). These levels were determined based on preliminary experiments. Eleven milliliters of each formulation was poured into $100-\mathrm{mm}$ polyethylene Petri dishes and dried in a convection oven $(10 \mathrm{GN} 1 / 1$; Voss-Electrolux, Syddanmark, Denmark) at $55^{\circ} \mathrm{C}$ for 3 h.

\section{Sensory Analysis of Formulation Candidates}

An untrained sensory panel (9 judges) was used to determine preferences among the set of 8 products that resulted from the $2^{3}$ factorial experimental design described previously. The panel evaluated 3 attributes among these products (film formation, homogeneity, and smoothness). Each attribute was graded from 1 to 5 (from worst to best). A rubric was provided to each member of the panel to describe what should be understood for ratings of $1,2,3,4$, or 5 for each attribute. Data were analyzed using Minitab 14 software (Minitab, State College, PA).

\section{Making of Probiotic Obleas}

The process of obtaining probiotic obleas consisted of fermenting whey with the probiotic strains and formulating it with prebiotic carbohydrates (inulin and RS) and gelatin. This preparation was poured onto a polytetrafluoroethylene-coated nonstick baking pan, stored at $4^{\circ} \mathrm{C}$ for $1 \mathrm{~h}$, and then dried in a convention oven under an airflow of $0.212 \pm 0.03 \mathrm{~m} / \mathrm{min}$. Finally, the obleas were dehydrated at room temperature $(23$ $\pm 2^{\circ} \mathrm{C}$ ) for $22 \mathrm{~h}$ in a desiccator at approximately $0 \%$ relative humidity (originated by $\mathrm{CaCl}_{2}$ ). Three drying temperatures $\left(40,55\right.$, and $70^{\circ} \mathrm{C}$ ) were evaluated in terms of the viability of the microorganisms after drying. Plate counts, using conventional synthetic MRS agar (Difco Laboratories) and the same incubation conditions as the fermentation, were conducted for the formulation (before drying) and for the dried product to calculate the proportion of bacteria that survived. The viability of microorganisms was also evaluated for the final product (after dehydration at approximately $0 \%$ relative humidity).

\section{RESULTS AND DISCUSSION}

\section{Fermentation Kinetics}

The kinetics of whey fermentation (cell growth, $\mathrm{pH}$, lactose consumption, and lactic acid production) with B. infantis ATCC 17930 and L. acidophilus ATCC 521 are shown in Figure 1. No lag phase was observed in the cell growth curves, suggesting that the strains were effectively adapted to whey. In all the fermentation experiments, the initial concentrations for B. infantis and L. acidophilus were set at 7.5 and $7.6 \log _{10} \mathrm{cfu} /$ $\mathrm{mL}$, respectively. Bacteria concentrations increased by 1 order of magnitude after the first hour of fermentation, achieving concentrations of $8.75 \pm 0.046$ and 8.71 $\pm 0.085 \log _{10} \mathrm{cfu} / \mathrm{mL}$ for B. infantis and L. acidophilus, respectively. Bifidobacterium infantis showed exponential growth during the first $4 \mathrm{~h}$ of fermentation and reached the stationary phase between the fourth and eighth hour. The specific growth rate $(\mu)$ and doubling time $\left(t_{d}\right)$ for this strain were $0.28 / \mathrm{h}$ and $2.25 \mathrm{~h}$, respectively.

Figure 1c shows the analogous cell growth curve of $L$. acidophilus cells. An exponential phase can be observed during the first $4 \mathrm{~h}$. From the fourth to the eighth hour of fermentation, a stationary phase occurred, followed by a death phase. The specific growth rate and doubling time were $0.31 / \mathrm{h}$ and $2.22 \mathrm{~h}$, respectively. As shown in Figures $1 \mathrm{~b}$ and $1 \mathrm{~d}$, the highest slopes of lactose consumption and lactic acid production occurred between the second and fourth hour of culture $(0.26$ and 0.35 $\mathrm{g} / \mathrm{L}$ per hour, respectively, for $B$. infantis, and 0.27 and $0.53 \mathrm{~g} / \mathrm{L}$ per hour for L. acidophilus). This behavior is consistent with the highest slopes in cell growth and $\mathrm{pH}$ evolution observed during this time frame. These results suggest that both strains experience their maximum growth rate and metabolic activity during the mid-exponential phase. Although the reported $\mathrm{pH}$ for optimal growth of $B$. infantis and L. acidophilus are 6 to 7 and 5.4 to 6.0 , respectively (Kailasapathy and Rybka, 1997; Damin et al., 2008), these strains were able to grow efficiently at lower $\mathrm{pH}$. These data suggest 

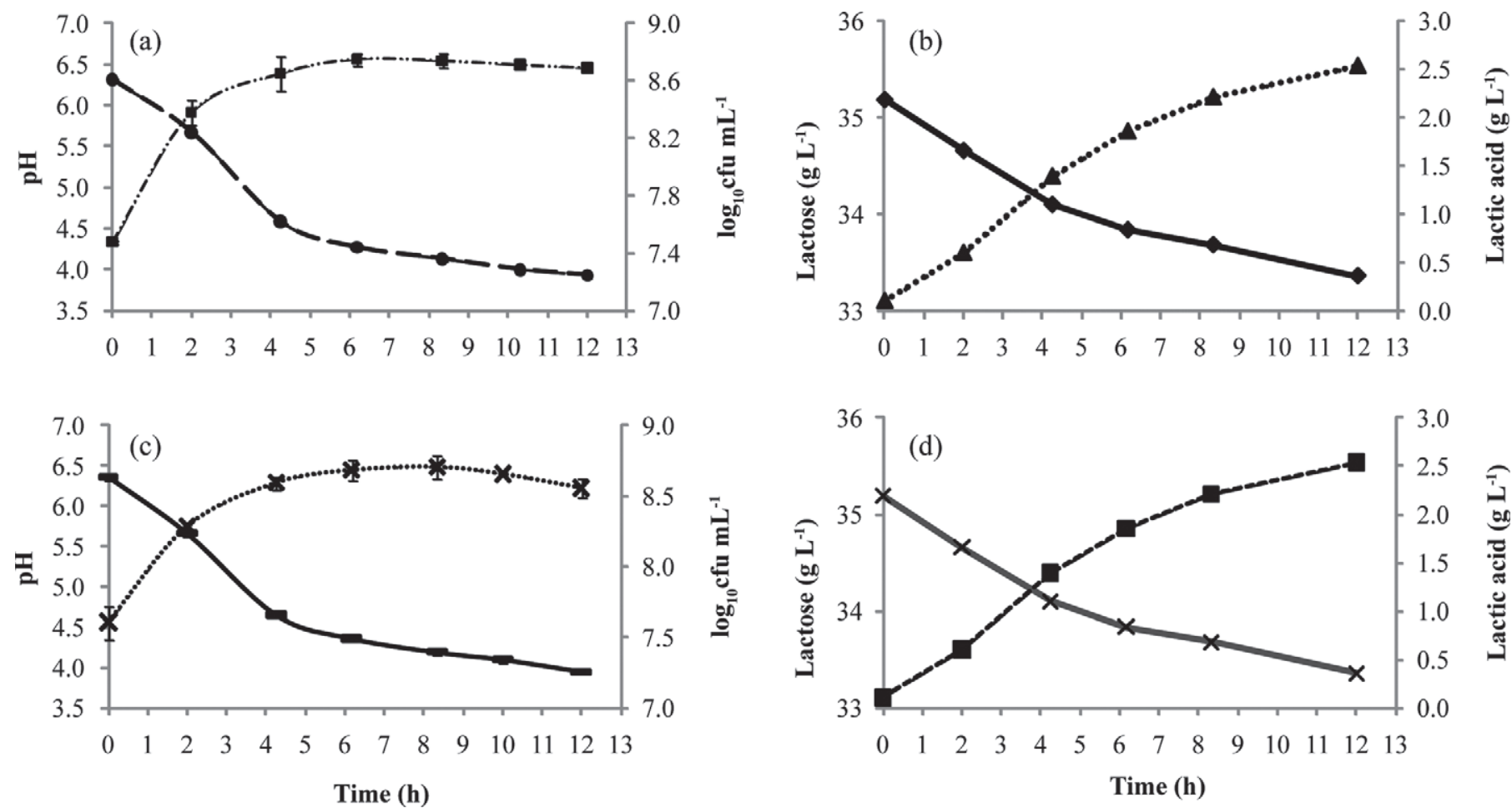

Figure 1. Whey fermentation curves: (a) bacterial growth (dotted-dashed line with squares) and $\mathrm{pH}$ (dashed line with circles) curves with Bifidobacterium infantis; (b) lactose (solid line with diamonds) and lactic acid (dotted line with triangles) concentration curves with B. infantis; (c) bacterial growth (dotted line with $\times \mathrm{s}$ ) and $\mathrm{pH}$ (solid line with rectangles) curves with Lactobacillus acidophilus; (d) lactose (solid line with $\times \mathrm{s}$ ) and lactic acid (dashed line with squares) concentration curves with L. acidophilus. Error bars represent standard deviation of 3 determinations.

that both strains were able to adapt their metabolism to more acidic conditions because of the successive transfer made in whey, which had an initial $\mathrm{pH}$ of 6.4.

Fermented whey in the mid-exponential phase was used in the formulation to develop probiotic obleas.
It has been reported that during this stage, bacteria increase their capacity to adapt to adverse conditions because they are able to produce "stress proteins" that allow them to create a homeostatic system under the new conditions (Olson and Aryana 2008). (a)

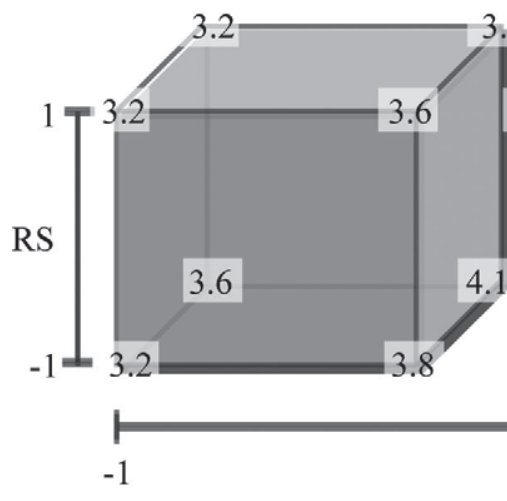

(b)

(c)

Figure 2. Cube plots: analysis of additive levels by an experimental factorial design to determine the formulation of the dehydrated and laminated probiotic product. Each axis corresponds to 1 additive on its low and high levels (8.33 and 16.66\%). The numbers on the corners correspond to averages obtained from the evaluations of 9 judges: (a) film formation; (b) homogeneity; (c) smoothness. RS = resistant corn starch type 2 . 


\section{Definition of Probiotic Oblea Formulation}

Information derived from the sensory analysis of the 8 products that resulted from the $2^{3}$ experimental design (Figures 2 and 3) was used to choose the best formulation in terms of the selected quality characteristics: film formation, homogeneity, and smoothness. Although our sensory study had limitations, particularly because of the use of a relatively small number of untrained judges, the opinions of all the judges were very consistent. For example, all judges selected the same formulation as the best. For every attribute, most judges concurred in their opinions of which formulation was the best. In the attribute of homogeneity, most judges evaluated the same formulation as the worst. Figure 2 shows cube plots in which each axis represents an ingredient. Each corner defines 1 of the 8 formulations investigated; the numbers displayed on the vertices are the averages of the ninth evaluation made (central point of the experimental design). The formulation with high levels of gelatin and inulin and a low level of RS had the highest average ratings of the 3 quality characteristics.

The effects of each one of the ingredients on the quality characteristics evaluated is presented in Figure 3. Our results suggest that a high level of inulin had a positive effect on all quality characteristics. In addition, although no significant effect of RS on homogeneity was observed, low levels of this ingredient appear to enhance smoothness and film formation. Gelatin seems to have a positive effect on homogeneity at a high level, whereas no significant effect on smoothness and film formation was observed. Although our statistical analysis was not sensitive enough to show significant differences (except for inulin and gelatin, which had significant effects on homogeneity; $P<0.05$ ), we observed that the factors and the levels selected in our experimental design resulted in obleas with different qualities. The graphs derived from the experimental analysis represented what we observed in practice very well, and we considered them a good tool for making decisions regarding the best formulation.

\section{Making of Probiotic Oblea}

Exposure to high temperatures and oxygen could be lethal for B. infantis and L. acidophilus (Kailasapathy, 2002). Both of these conditions occur during drying. In this study, we evaluated the effect of drying at 3 different temperature conditions on the viability of probiotic bacteria in the final product. Table 1 shows the drying temperatures studied, the moisture content after drying, the viable bacteria count before and after drying, and the proportion of probiotic bacteria that survived the drying process. In all cases, the concentration of viable probiotic bacteria after drying was higher than $7 \log _{10} \mathrm{cfu} / \mathrm{g}$ (equivalent to $10^{7} \mathrm{cfu} / \mathrm{g}$ ). However, the highest concentrations and survival proportions were achieved at $55 \pm 5^{\circ} \mathrm{C}$ for both strains. Drying at $40 \pm$ $5^{\circ} \mathrm{C}$ and $55 \pm 5^{\circ} \mathrm{C}$ resulted in comparable levels of viability in the product, but at the lower temperature, the

(a)

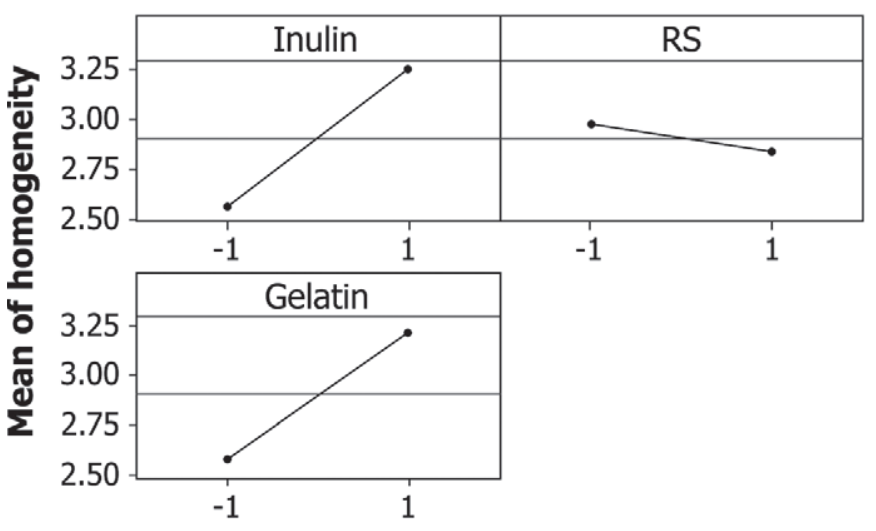

(b)

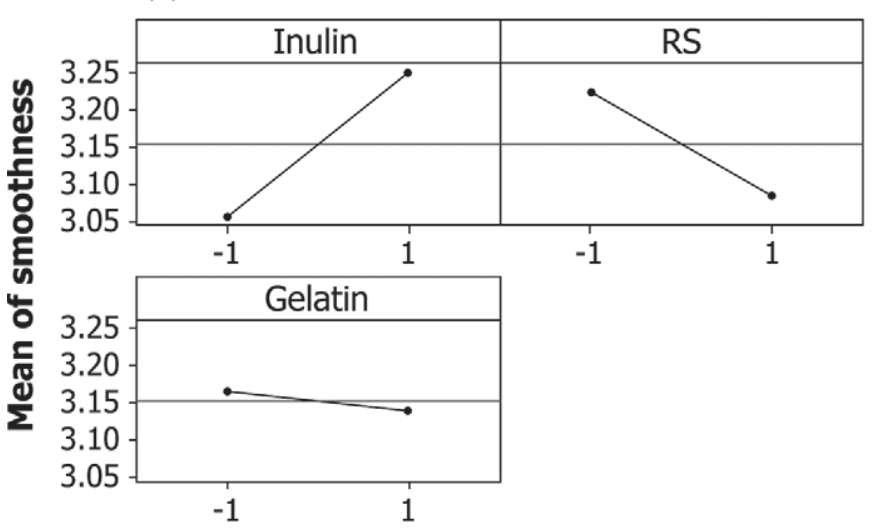

(c)

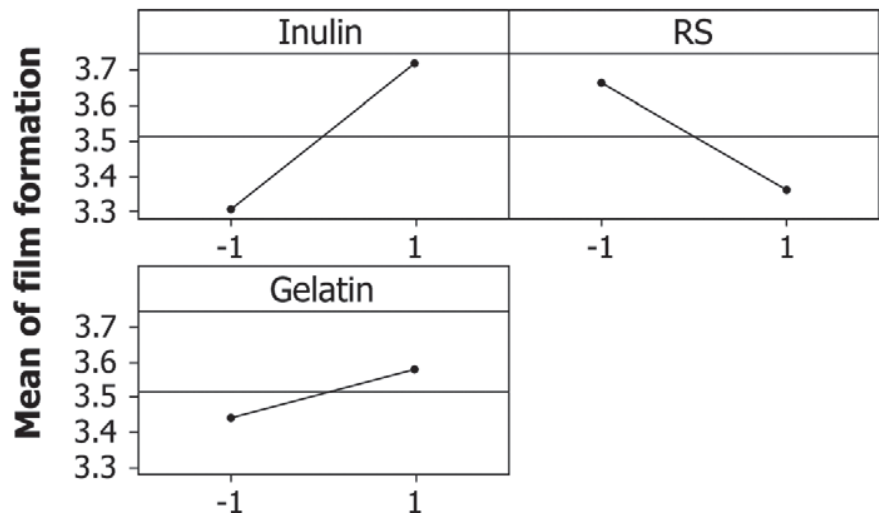

Figure 3. Effects of inulin, gelatin, and resistant starch (RS) on the quality characteristics of the dehydrated and laminated probiotic product: (a) homogeneity; (b) smoothness; (c) film formation. 
Table 1. Rubric used in the sensory analysis of formulations

\begin{tabular}{cll}
\hline Grade & Classification & Description \\
\hline $\begin{array}{cl}\text { Film formation } \\
1\end{array}$ & Very unsatisfactory & $\begin{array}{l}\text { The dried sample shows no integrity. The sample has small, separated (independent), and } \\
\text { very dry flakes. }\end{array}$ \\
2 & Unsatisfactory & $\begin{array}{l}\text { The dried sample shows no total integrity. The flakes are partially amalgamated. } \\
\text { The dried sample is a film with a cracked appearance. }\end{array}$ \\
3 & $\begin{array}{l}\text { Regular } \\
\text { Satisfactory }\end{array}$ & $\begin{array}{l}\text { The dried sample is a uniform film. } \\
\text { The dried sample is a uniform film with a plastic appearance. }\end{array}$ \\
5 & Very satisfactory & \\
Homogeneity & Very unsatisfactory & The sample presents opaque and translucent zones that are very delimited. \\
1 & Unsatisfactory & The sample presents segregated zones that are more opaque than the rest of the sample. \\
2 & Regular & The sample has a mosaic appearance (small opaque zones are distributed uniformly \\
3 & throughout the sample). \\
4 & Satisfactory & The sample has a uniform appearance but with very small and few opaque zones. \\
5 & Very satisfactory & The entire sample has a very uniform appearance. \\
Smoothness & Very unsatisfactory & The entire film area shows wrinkles, ranging from moderate to substantial. \\
1 & Unsatisfactory & The entire film area shows moderate wrinkles. \\
2 & Regular & More than the $50 \%$ of the film is smooth; the rest shows moderate wrinkles. \\
3 & Satisfactory & A few portions of the film show slight waviness. \\
4 & Very satisfactory & The film is totally smooth. \\
5 & &
\end{tabular}

operation time was approximately $79 \%$ longer and the moisture in the product was approximately $1 \%$ higher. Consequently, drying at $55 \pm 5^{\circ} \mathrm{C}$ is recommended. Under this condition, a product with $9.47 \pm 1.2 \%$ of final moisture was obtained. This moisture content conferred plasticity on the matrix, which facilitated peeling of the product from the pan surface.

A final dehydration step was necessary to decrease the moisture content from 9.47 to $3.5 \%$ to obtain a drycrispy laminated product. Consequently, after drying, the product was subjected to a $0 \%$ relative humidity environment. To determine whether this final dehydration process would affect bacterial viability, the concentration of live cells in the final product was determined. Table 2 shows the results of viable bacteria concentration before and after the dehydration process. The viable cell concentration decreased by $0.7 \pm 0.249 \%$ and $1.83 \pm 0.425 \%$ for B. infantis and L. acidophilus, respectively. Future studies should determine the shelf life of the probiotic oblea, namely, the concentration of viable bacteria as a function of time at different storage conditions.

The unexpectedly high survival of $B$. infantis and L. acidophilus (Tables 2 and 3), even at the highest drying temperature studied $\left(75^{\circ} \mathrm{C}\right)$, suggests that some of the ingredients used in the formulation may act as protectants for probiotic bacteria. Previous studies have used inulin, RS, and gelatin to microencapsulate or immobilize cells and keep them viable during their shelf life and along the gastrointestinal tract (Carrillo, 2006; Farnworth, 2008; Malmo et al., 2011). Some other mechanisms may at least partially explain survival dur-

Table 2. Influence of drying temperature and time on Bifidobacterium infantis and Lactobacillus acidophilus viability ${ }^{1}$

\begin{tabular}{|c|c|c|c|c|c|c|}
\hline \multirow[b]{2}{*}{ Strain } & \multirow[b]{2}{*}{$\begin{array}{c}\text { Drying } \\
\text { temperature }\left({ }^{\circ} \mathrm{C}\right)\end{array}$} & \multirow[b]{2}{*}{$\begin{array}{l}\text { Drying } \\
\text { time }(\mathrm{h})\end{array}$} & \multirow[b]{2}{*}{$\begin{array}{c}\mathrm{H}_{2} \mathrm{O} \text { after } \\
\text { drying (\%) }\end{array}$} & \multicolumn{3}{|c|}{ Viability $\left(\log _{10} \mathrm{cfu} / \mathrm{g}\right)$} \\
\hline & & & & $\begin{array}{l}\text { Before drying } \\
\text { (dry basis) }\end{array}$ & $\begin{array}{l}\text { After drying } \\
\text { (dry basis) }\end{array}$ & $\begin{array}{c}\text { Before drying/ } \\
\text { after drying }\end{array}$ \\
\hline \multirow[t]{3}{*}{ B. infantis } & $40 \pm 5$ & $4.75 \pm 0.7^{2}$ & $10.46 \pm 1.2^{3}$ & $9.69 \pm 0.047^{3}$ & $9.49 \pm 0.063^{3}$ & $0.98 \pm 0.003^{3}$ \\
\hline & $55 \pm 5$ & $2.66 \pm 0.22^{2}$ & $9.47 \pm 1.2^{3}$ & $9.81 \pm 0.154^{4}$ & $9.63 \pm 0.136^{4}$ & $0.98 \pm 0.002^{4}$ \\
\hline & $70 \pm 5$ & $1.8 \pm 0.19^{2}$ & $8.98 \pm 1.3^{3}$ & $9.67 \pm 0.020^{5}$ & $8.19 \pm 0.028^{5}$ & $0.85 \pm 0.002^{5}$ \\
\hline \multirow[t]{3}{*}{ L. acidophilus } & $40 \pm 5$ & $4.75 \pm 0.75^{2}$ & $10.46 \pm 1.2^{3}$ & $9.75 \pm 0.021^{6}$ & $9.45 \pm 0.006^{6}$ & $0.97 \pm 0.002^{6}$ \\
\hline & $55 \pm 5$ & $2.66 \pm 0.22^{2}$ & $9.47 \pm 1.2^{3}$ & $9.79 \pm 0.066^{4}$ & $9.55 \pm 0.058^{4}$ & $0.97 \pm 0.002^{4}$ \\
\hline & $70 \pm 5$ & $1.8 \pm 0.19^{2}$ & $8.98 \pm 1.3^{3}$ & $9.73 \pm 0.011^{5}$ & $9.03 \pm 0.011^{5}$ & $0.93 \pm 0.0004^{5}$ \\
\hline
\end{tabular}

${ }^{1}$ Averages and SD of independent experiments. The initial water content of the formula was $92.77 \pm 1.16 \mathrm{~g}$ of $\mathrm{H}_{2} \mathrm{O} / 100 \mathrm{~g}$ of dry mass.

${ }^{2}$ Data of 6 experiments.

${ }^{3}$ Data of 4 experiments.

${ }^{4}$ Data of 8 experiments.

${ }^{5}$ Data of 3 experiments.

${ }^{6}$ Data of 5 independent experiments. 
Table 3. Evaluation of viable probiotic bacteria concentrations after final dehydration ${ }^{1}$

\begin{tabular}{lcr}
\hline & \multicolumn{2}{c}{ Viability $\left(\log _{10} \mathrm{cfu} / \mathrm{g}\right.$, dry basis $)$} \\
\cline { 2 - 3 } Item & $\begin{array}{c}\text { Bifidobacterium } \\
\text { infantis }\end{array}$ & $\begin{array}{c}\text { Lactobacillus } \\
\text { acidophilus }\end{array}$ \\
\hline Process stage $^{2}$ & $9.70 \pm 0.018$ & $9.58 \pm 0.055$ \\
First drying $^{2}$ & $9.64 \pm 0.015$ & $9.41 \pm 0.065$ \\
Final dehydration $^{3}$ & $99.3 \pm 0.249$ & $98.17 \pm 0.425$ \\
\hline Survival (\%) &
\end{tabular}

${ }^{1}$ Final survival percentages considering the first drying. Data are representative of 3 independent experiments. Dry basis refers to dry basis of the dehydrated and laminated probiotic product.

${ }^{2}$ Drying in a convection oven at $55^{\circ} \mathrm{C}$ for $2.66 \mathrm{~h}$.

${ }^{3}$ Dehydration in a hermetic chamber at $22^{\circ} \mathrm{C}$ and approximately $0 \%$ relative humidity for $22 \mathrm{~h}$.

ing drying: the production of stress proteins to resist hostile environmental conditions (Olson and Aryana, 2008); the accumulation of sugars, such as trehalose and sucrose, or compatible solutes, such as betaine and carnitine; and bacterial aggregation (Kets et al., 1996; Zayeda and Roos, 2004; Todorov et al., 2012).

Once we had determined the most successful formulation, as well as the effect of drying conditions and the final dehydration on probiotic viability, the process for developing a probiotic oblea was defined.

\section{CONCLUSIONS}

A process of obtaining an oblea dessert with probiotic bacteria (B. infantis or L. acidophilus) was successfully developed. The key steps in the process consisted of fermenting whey with B. infantis or L. acidophilus; formulating the fermented whey with RS, inulin, and gelatin; drying in a convection oven at $55 \pm 5^{\circ} \mathrm{C}$ for $2.66 \mathrm{~h}$; and dehydrating at $22^{\circ} \mathrm{C}$ and approximately $0 \%$ relative humidity for $22 \mathrm{~h}$. Remarkably, after drying at high temperatures $\left(55 \pm 5^{\circ} \mathrm{C}\right)$, the concentration of viable probiotic bacteria remained above the minimum acceptable concentration $\left(10^{7} \mathrm{cfu} / \mathrm{g}\right)$ for a probiotic product. Therefore, in addition to their anticipated functions in the formulation (film formation, homogeneity, and smoothness), the additives used (inulin, gelatin, and RS) played an important role in protecting bacteria from hostile conditions during processing (particularly drying). Further studies are needed to evaluate the viability of probiotic bacteria during the extended shelf life of the probiotic oblea.

\section{ACKNOWLEDGMENTS}

We gratefully acknowledge the financial support of Catedra Nutrigenómica (Centro de Biotecnología
FEMSA, Tecnológico de Monterrey, Monterrey, Nuevo León, México), Conacyt (México City, México), TIC Gums (México City, México), Caprico (Linares Nuevo León, México), and National Starch (México City, México). We are grateful to Mario Menjivar (Industrias La Constancia, San Salvador, El Salvador) for the technical support provided during the bacterial reactivation stage, and to Mario Álvarez (Centro de Biotecnología FEMSA, Tecnológico de Monterrey, Monterrey, Nuevo León, México) for his valuable assistance in the final preparation of this article.

\section{REFERENCES}

Aguirre-Ezkauriatza, E. J., J. M. Aguilar-Yáñez, A. Ramírez-Medrano, and M. M. Alvarez. 2010. Production of probiotic biomass (Lactobacillus casei) in goat whey: Comparison of batch, continuous and fed-batch cultures. Bioresour. Technol. 101:2837-2844. http://dx.doi.org/10.1016/j.biortech.2009.10.047.

Araújo, E. A., A. F. de Carvalho, E. S. Leandro, M. M. Furtado, and C. A. de Moraes. 2010. Development of a symbiotic cottage cheese added with Lactobacillus delbrueckii UFV H2b20 and inulin. J. Funct. Foods 2:85-89.

Carrillo Aguado, J. 2006. Tratamiento y reutilización del suero de leche. Mundo Lácteo Cárnico (México) Nov./Dec.:27-30.

Chávarri, M., I. Marañón, R. Ares, F. C. Ibáñez, F. Marzo, and M. C. Villarán. 2010. Microencapsulation of a probiotic and prebiotic in alginate-chitosan capsules improves survival in simulated gastrointestinal conditions. Int. J. Food Microbiol. 142:185-189.

Chen, S., Q. Zhao, L. R. Ferguson, Q. Shu, I. Weir, and S. Garg. 2012. Development of a novel probiotic delivery system based on microencapsulation with protectants. Appl. Environ. Microbiol. 93:1447-1457. http://dx.doi.org/10.1007/s00253-011-3609-4.

Damin, M. R., E. Minowa, M. R. Alcantara, and M. N. Oliveira. 2008. Effect of cold storage on culture viability and some rheological properties of fermented milk prepared with yogurt and probiotic bacteria. J. Texture Stud. 39:40-55.

de Barcellos, M. D., and R. L. Lionello. 2011. Consumer market for functional foods in south Brazil. Int. J. Food Syst. Dyn. 2:126144.

Farnworth, E. R. 2008. The evidence to support health claims for probiotics. J. Nutr. 138:1250S-1254S.

García-Garibay, M., R. Quintero-Ramírez, and C. A. López-Murguía. 2002. Biotecnología Alimentaría. Editorial Limusa, México, Distrito Federal, México.

Heidebach, T., P. Först, and U. Kulozik. 2010. Influence of caseinbased microencapsulation on freeze-drying and storage of probiotic cells. J. Food Eng. 98:309-316.

Hernandez-Izquierdo, V. M., and J. M. Krochta. 2008. Thermoplastic processing of proteins for film formation-A review. J. Food Sci. 73:R30-R39.

Jankovic, I., W. Sybesma, P. Phothirath, E. Ananta, and A. Mercenier. 2010. Application of probiotics in food products - Challenges and new approaches. Curr. Opin. Biotechnol. 21:175-181.

Kailasapathy, K. 2002. Microencapsulation of probiotic bacteria: Technology and potential applications. Curr. Issues Intest. Microbiol. 3:39-48.

Kailasapathy, K. 2006. Survival of free and encapsulated probiotic bacteria and their effect on the sensory properties of yoghurt. Lebenson. Wiss. Technol. 39:1221-1227.

Kailasapathy, K., and S. Rybka. 1997. L. acidophilus and Bifidobacterium spp.: Their therapeutic potential and survival in yogurt. Aust. J. Dairy Technol. 52:28-35.

Kets, E., P. Teunissen, and J. de Bont. 1996. Effect of compatible solutes on survival of lactic acid bacteria subjected to drying. Appl. Environ. Microbiol. 62:259-261. 
Klayraung, S., H. Viernstein, and S. Okonogi. 2009. Development of tablets containing probiotics: Effects of formulation and processing parameters on bacterial viability. Int. J. Pharm. 370:54-60.

Konieczna, P., D. Groeger, M. Ziegler, R. Frei, R. Ferstl, F. Shanahan, E. M. M. Quigley, B. Kiely, C. A. Akdis, and L. O'Mahony. 2012. Bifidobacterium infantis 35624 administration induces Foxp3 $\mathrm{T}$ regulatory cells in human peripheral blood: Potential role for myeloid and plasmacytoid dendritic cells. Gut 61:354-366.

Le Leu, R. K., Y. Hu, I. L. Brown, R. J. Woodman, and G. P. Young. 2010. Synbiotic intervention of Bifidobacterium lactis and resistant starch protects against colorectal cancer development in rats. Carcinogenesis $31: 246-251$.

Magalhães, K. T., M. A. Pereira, A. Nicolau, G. Dragone, L. Domingues, J. A. Teixeira, J. B. de Almeida Silva, and R. F. Schwan. 2010. Production of fermented cheese whey-based beverage using kefir grains as starter culture: Evaluation of morphological and microbial variations. Bioresour. Technol. 101:8843-8850.

Malmo, C., A. L. Storia, and G. Mauriello. 2011. Microencapsulation of Lactobacillus reuteri DSM 17938 cells coated in alginate beads with chitosan by spray drying to use as a probiotic cell in a chocolate soufflé. Food Bioprocess Technol. In press. http://dx.doi. org/10.1007/s11947-011-0755-8.

McKinnon, A., and J. Campbell. 1998. Quick-response in the frozen food supply chain: The manufacturer's perspective. Christian Salvesen Logistics Research Paper No. 2. Heriot-Watt University, Edinburgh, UK. Accessed Aug. 12, 2012. http://www.som.hw.ac.uk/ $\operatorname{logistics/pdf/cs2.pdf.~}$

Olson, D. W., and K. J. Aryana. 2008. An excessively high Lactobacillus acidophilus inoculation level in yogurt lowers product quality during storage. Lebenson. Wiss. Technol. 41:911-918.

Parkes, G. C., J. D. Sanderson, and K. Whelan. 2010. Treating irritable bowel syndrome with probiotics: The evidence. Proc. Nutr. Soc. 69:187-194. http://dx.doi.org/10.1017/S002966511000011X.
Pereira, D. I. A., and G. R. Gibson. 2002. Cholesterol assimilation by lactic acid bacteria and bifidobacteria isolated from the human gut. Appl. Environ. Microbiol. 68:4689-4693. http://dx.doi. org/10.1128/AEM.68.9.4689-4693.2002.

Ramirez-Farias, C., K. Slezak, Z. Fuller, A. Duncan, G. Holtrop, and P. Louis. 2009. Effect of inulin on the human gut microbiota: Stimulation of Bifidobacterium adolescentis and Faecalibacterium prausnitzii. Br. J. Nutr. 101:541-550.

Rivera-Espinoza, Y., and Y. Gallardo-Navarro. 2010. Non-dairy probiotic products. Food Microbiol. 27:1-11.

Scharl, M., S. Geisel, S. R. Vavricka, and G. Rogler. 2011. Dying in yoghurt: The number of living bacteria in probiotic yoghurt decreases under exposure to room temperature. Digestion 83:13-17.

Soares, D. S., A. E. C. Fai, A. M. Oliveira, E. M. F. Pires, and T. L. M. Stamford. 2011. The use of cheese whey for probiotic yogurt production. Arq. Bras. Med. Vet. Zoo. 63:996-1002.

Sultana, K., G. Godward, N. Reynolds, R. Arumugaswamy, P. Peiris, and K. Kailasapathy. 2000. Encapsulation of probiotic bacteria with alginate-starch and evaluation of survival in simulated gastrointestinal conditions and in yogurt. Int. J. Food Microbiol. 62:47-55.

Todorov, S. D., J. G. LeBlanc, and B. D. G. M. Franco. 2012. Evaluation of the probiotic potential and effect of encapsulation on survival for Lactobacillus plantarum ST16Pa isolated from papaya. World J. Microbiol. Biotechnol. 28:973-984. http://dx.doi. org/10.1007/s11274-011-0895-z.

Zayeda, G., and Y. H. Roos. 2004. Influence of trehalose and moisture content on survival of Lactobacillus salivarius subjected to freezedrying and storage. Process Biochem. 39:1081-1086.

Zhu, H., Z. Li, S. Mao, B. Ma, S. Zhou, L. Deng, T. Liu, D. Cui, Y. Zhao, J. He, C. Yi, and Y. Huang. 2011. Antitumor effect of sFlt1 gene therapy system mediated by Bifidobacterium infantis on Lewis lung cancer in mice. Cancer Gene Ther. 18:884-896. 